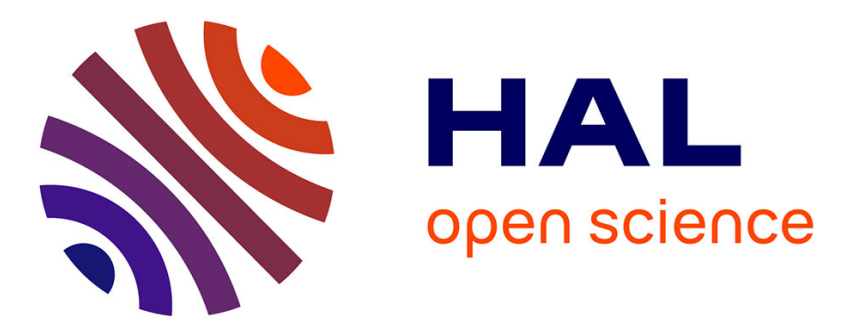

\title{
Occupational exposure to wood dust and risk of lung cancer the ICARE study
}

Mireille Matrat, Loredana Radoï, Joëlle Févotte, Florence Guida, Sylvie

Cénée, Diane Cyr, Marie Sanchez, Gwenn Menvielle, Annie Schmaus, Emilie

Marrer, et al.

\section{To cite this version:}

Mireille Matrat, Loredana Radoï, Joëlle Févotte, Florence Guida, Sylvie Cénée, et al.. Occupational exposure to wood dust and risk of lung cancer the ICARE study. Occupational and Environmental Medicine, 2019, 76 (12), pp.901-907. 10.1136/oemed-2019-105802 . hal-02304998

\section{HAL Id: hal-02304998 \\ https://hal-univ-rennes1.archives-ouvertes.fr/hal-02304998}

Submitted on 3 Feb 2020

HAL is a multi-disciplinary open access archive for the deposit and dissemination of scientific research documents, whether they are published or not. The documents may come from teaching and research institutions in France or abroad, or from public or private research centers.
L'archive ouverte pluridisciplinaire HAL, est destinée au dépôt et à la diffusion de documents scientifiques de niveau recherche, publiés ou non, émanant des établissements d'enseignement et de recherche français ou étrangers, des laboratoires publics ou privés. 
OCCUPATIONAL EXPOSURE TO WOOD DUST AND RISK OF LUNG CANCER: THE ICARE STUDY

Mireille Matrat,,${ }^{1,2,3}$ Loredana Radoï, ${ }^{1,4}$ Joëlle Févotte, ${ }^{5}$ Florence Guida, ${ }^{1}$ Sylvie Cénée, ${ }^{1}$ Diane Cyr, ${ }^{6,7}$ Marie Sanchez, ${ }^{1}$ Gwenn Menvielle, ${ }^{8}$ Annie Schmaus, ${ }^{6,7}$ Emilie Marrer, ${ }^{9}$ Danièle Luce, ${ }^{10,11}$ Isabelle Stücker, ${ }^{1}$ Icare Study Group ${ }^{12}$

\section{Corresponding author}

Mireille Matrat

Centre de recherche en Epidémiologie et Santé des Populations (CESP), INSERM U1018 Equipe Cancer et Environnement, Bâtiment INSERM 15/16, 16 av. Paul Vaillant Couturier, F-94807 VILLEJUIF Cedex,

Email: mireille.matrat@ inserm.fr

Phone: 0033145596040

Members of ICARE study group: Registre des cancers du Calvados, France (Anne-Valérie Guizard); Registre des cancers du Doubs et du Territoire de Belfort, France (Arlette Danzon, Anne-Sophie Woronoff); Registre des cancers du Bas-Rhin, France (Velten Michel); Registre des cancers du HautRhin, France (Antoine Buemi, Émilie Marrer); Registre des cancers de l’Hérault, France (Brigitte Tretarre); Registre des cancers de l'Isère, France (Marc Colonna, Patricia Delafosse); Registre des cancers de Loire-Atlantique-Vendée, France (Paolo Bercelli, Florence Molinie); Registre des cancers de la Manche, France (Simona Bara); Registre des cancers de la Somme, France (Benedicte LapotreLedoux, Nicole Raverdy); Inserm, Centre for Research in Epidemiology and Population Health (CESP), U1018, Environmental Epidemiology of Cancer Team, F-94807, Villejuif, France (Oumar Gaye, Farida Lamkarkach), Institut national de Veille Sanitaire (InVS), 94410 Saint-Maurice, France (Corinne Pilorget).

Author affiliations

${ }^{1}$ Université Paris-Saclay, Université Paris-Sud, UVSQ, CESP, INSERM, Equipe Epidémiologie des cancers, gènes et environnement, Villejuif, France

${ }^{2}$ Faculté de médecine, Université Paris Est Créteil, Créteil, France

${ }^{3}$ Centre Hospitalier Intercommunal, Service des Pathologies Professionnelles et de l'Environnement, Créteil, France

${ }^{4}$ Faculté de chirurgie dentaire, Université Paris Descartes, Montrouge, France

${ }^{5}$ Unité Mixte de Recherche Epidémiologique et de Surveillance Transport Travail Environnement

(UMRESTTE), Université Claude Bernard Lyon 1, Lyon, France

${ }^{6}$ Inserm, Population-based Epidemiologic Cohorts Unit, UMS 011, Villejuif, France

${ }^{7}$ Versailles St-Quentin University, UMS 011, F-94807, Villejuif, France

${ }^{8}$ Sorbonne Universités, UMPC University Paris 06, Institut Pierre Louis d'Epidémiologie et de Santé Publique (IPLESP, UMRS 1136), Paris, France

${ }^{9}$ Registre des tumeurs du Haut Rhin, Centre hospitalier de Mulhouse ARER 68, France

${ }^{10}$ INSERM U1085, IRSET, campus de Fouillole, Pointe à Pitre, Guadeloupe

${ }^{11}$ Université de Rennes 1, campus de Fouillole, Pointe à Pitre, Guadeloupe

${ }^{12}$ INSERM U1018 Equipe Epidémiologie des cancers, gènes et environnement, Bâtiment INSERM 15/16, 16 avenue Paul Vaillant Couturier, Villejuif, France 


\section{Keywords}

Wood dust

Asbestos

Lung cancer

Case-control study

Epidemiology 
MAIN TEXT 


\section{ABSTRACT}

\section{OBJECTIVES}

In a previous analysis of data from a French population-based case-control study (the Investigation of occupational and environmental Causes of Respiratory cancers (ICARE) study), 'having ever worked' in wood-related occupations was associated with excess lung cancer risk after adjusting for smoking but not for occupational factors. The present study aimed to investigate the relationship between lung cancer risk and wood dust exposure after adjusting for occupational exposures.

\section{METHODS}

Data were obtained from 2,276 cases and 2,780 controls on smoking habits and lifelong occupational history, using a standardized questionnaire with a job-specific questionnaire for wood dust exposure. Logistic regression models were used to calculate odds ratios and 95\% confidence intervals adjusted for age, area of residence, tobacco smoking, the number of job periods, and exposure to silica, asbestos and diesel motor exhaust (DME).

\section{RESULTS}

No significant association was found between lung cancer and wood dust exposure after adjustment for smoking, asbestos, silica and DME exposures. The risk of lung cancer was slightly increased among those who were exposed to wood dust more than 10 years, and had over 40 years since the first exposure.

\section{CONCLUSION}

Our findings do not provide a strong support to the hypothesis that wood dust exposure is a risk factor for lung cancer. This study showed the importance of taking into account smoking and occupational co-exposures in studies on lung cancer and wood dust exposure. Further studies evaluating the level and frequency of exposure during various tasks in wood work are needed. 


\section{KEY MESSAGES}

\section{What is already known about this subject?}

Few studies found a statistically significantly increased risk of lung cancer with wood dust exposure and none distinguished wood species or tasks performed. Few studies adjusted accurately for occupational exposures.

\section{What are the new findings?}

Our case-control population-based study included a broader range of exposure circumstances to wood dust. The association between lung cancer and wood dust exposure observed in the overall study population, but also among workers with a confined activity, was not confirmed after adjusting for smoking, asbestos, silica, and diesel motor exhaust exposures.

\section{How might this impact on policy or clinical practice in the foreseeable future?}

This study did not provide enough evidence for the role of wood dust exposure in the lung cancer occurrence. However, it showed the importance of taking into account co-exposures to established lung carcinogens in occupational studies on lung cancer and wood dust exposure. 


\section{OCCUPATIONAL EXPOSURE TO WOOD DUST AND RISK OF LUNG CANCER: THE ICARE STUDY}

\section{INTRODUCTION}

In France, 369,600 workers (1.7\%) were occupationally exposed to wood dust in 2010.[1] Wood dust was classified as carcinogenic to humans by the International Agency for Research on Cancer (IARC) with sufficient evidence for cancers of the nasal cavity, paranasal sinus, and nasopharynx,[2] and a strong evidence of an association between sinonasal cancer and exposure to hardwood dust. The evidence was weaker for lung cancer, with heterogeneous results: some case-control studies showed an excess risk associated with wood dust exposure, but none of the cohort studies confirmed these findings.[2]

Since that assessment by the IARC, a meta-analysis of 85 studies found a significantly increased risk of lung cancer associated with wood dust exposure (relative risk [RR] 1.21, 95\% confidence interval [CI] 1.05 to 1.39). This association did not depend on the method used to assess for wood dust exposure, and remained significant among studies that adjusted for smoking.[3] However, strong differences were observed according to the geographic region: wood dust was associated with a significantly decreased risk of lung cancer among studies from the Nordic countries where exposure was due predominantly to softwood. This suggested a differential effect of softwoods and hardwoods, but no study on lung cancer distinguished between wood species. Another possible source of the heterogeneity in the findings on lung cancer and wood dust is confounding by other occupational lung carcinogens. To our knowledge nine studies accounted for other occupational factors: asbestos;[4-6] asbestos and silica;[7] asbestos, and formaldehyde;[8] employment in occupations/industries with exposure to asbestos, arsenic, polycyclic aromatic hydrocarbons, nickel or chromium;[9] exposure to any of the confirmed or suspected human carcinogens;[10] and IARC group 1 known carcinogens;[11] in List A or B.[12] The list A or B industry/occupation carcinogens include those with a known or suspected increased lung cancer risk.[13-15] Three of these studies found a statistically significant increase in lung cancer risk with wood dust exposure. However two of the studies included no details about woodwork.[4,6] and the exposures to hardwood and softwood were combined in the analysis of the third study notwithstanding the detailed technical probing for some occupations.[11]

In a previous work based on the ICARE (Investigation of occupational and environmental Causes of Respiratory cancers) study data, having ever worked in wood-related occupations was associated with an excess risk of lung cancer (odds ratio [OR] 1.5, 95\% CI 1.0 to 2.1) after adjustment for smoking but not for other occupational exposures.[16] The aim of the present study was to investigate the relationship between lung cancer risk and occupational exposure to wood dust, taking into account smoking and occupational exposure to asbestos, silica and diesel motor exhaust. We also examined for the influence of the type of wood (hard or soft-wood) and work tasks (sawing/planing or sanding, manually or mechanically, among others), which are poorly evaluated in the literature. 


\section{METHODS}

\section{Study design}

ICARE is a large multicenter population-based case-control study on respiratory tract cancers conducted in France between 2001 and 2007 in 10 geographical areas (“départements”) covered by a cancer registry (see ref [17] for details). All lung cancer patients (aged between 18 and 75), identified during the study period, were eligible. The cases were all histologically confirmed primary lung cancers (International Classification of Diseases for Oncology ICD-O C33-C34), and all histological types were included. Participation in the study was proposed to 3,360 patients, but 434 refused (13\%). Throughout the recruitment period, population-based controls were randomly selected by a polling institute from the same "départements" as the cases. They were frequency-matched to cases by gender and age ( $<50$, [50-59, 60-69, and $\geq 70$ years) and were comparable to the general population in each “département” by socio-economic status ${ }^{1}$. Among the 4,673 eligible controls, 4,411 were contacted and 3,555 agreed to participate in the study (response rate 81\%).

Each participant gave written and informed consent. The study was approved by the Institutional Review Board of the French National Institute of Health and Medical Research (IRB-INSERM, $n^{\circ} 01-$ 036) and by the French Data Protection Authority (CNIL n90120).

\section{Data collection and occupational data coding}

Face-to-face interviews were conducted by trained interviewers using standardized questionnaires. The general questionnaire was used to collect lifelong occupational history, including the start and end date for each job, industry type, and a description of the tasks carried out. Participants who were too sick to provide answers - 60 controls and 202 cases - were interviewed with a shorter questionnaire (completed either by themselves or a next-of-kin) but they were excluded from the present study. Each occupation lasting one month or more was defined as a 'job period'. In addition, 20 job-specific questionnaires were used to obtain information on certain tasks or job titles, including woodworking. Occupations and industry branches were coded by trained coders (who were blinded to the status of participants as either a case or control), according to the International Standard Classification of Occupations (ISCO) and the French Nomenclature of Activities (Nomenclature d'Activités Françaises [NAF]).[18,19]

\section{Wood dust exposure and assessment of individual's exposure}

Occupational exposure to wood dust was first investigated for each job period with a single question in the general questionnaire: “During this job period, were you exposed to wood dust?". If the answer

\footnotetext{
${ }^{1}$ farmers, self-employed workers, managers/professional, intermediate occupations, clerical workers, sales and services workers, blue-collar workers, inactive individuals
} 
was yes, participants were asked to provide the frequency of exposure (in hours per day, per week, or in days per week, per month, or per year). Participants who were exposed to wood dust over $5 \%$ of their worktime in this job (i.e. over $1 / 2$ hour per day or 2 hours per week or 1 day per month), had to answer a job-specific questionnaire investigating the species of wood used, and the tasks performed (sanding or sawing of the wood mechanically or manually, and applying any treatment on the wood). A worker was classified as "sanding and sawing" when he declared that he sawed and sanded at least once during the professional career ("only sanding” when he only sanded; "only sawing” when he only sawed; and "nor sanding nor sawing" when he did neither).

In the specific questionnaire, when the workers declared that they have ever been exposed to:

- hardwood species in general or to birch, oak, chestnut, beech or walnut; he was considered as having been exposed to "hardwood",

- softwood species in general or to pine, fir or larch; he was considered as having been exposed to "softwood",

- composite wood among chipboard, plywood, medium-density fibreboard or melamine; he was considered as having been exposed to "composite wood",

- teak or another exotic wood; he was considered as having been exposed to "exotic wood".

The different categories were not mutually exclusive. The reference group included participants who had never been exposed to wood dust during their entire occupational history.

Each participant's exposure to wood dust was assessed by the following exposure indices:

- the duration of exposure to wood dust corresponding to the sum of the durations of each job period exposed to wood dust,

- $\quad$ the number of years since the first wood dust exposure.

We additionally conducted analyses among workers supposed to be exposed to a higher level of wood dust: workers who worked indoors and had no suction system at the workplace.

\section{Assessment of smoking, silica, diesel motor exhaust and asbestos exposure}

Lifelong cigarette smoking was measured using the comprehensive smoking index (CSI), which takes into account the total duration of smoking, time since cessation and average number of cigarettes smoked per day.[20]

To assess occupational exposure to silica, we used a specific silica job-exposure matrix (JEM) used in another ICARE study.[21,22] The silica-JEM assigned a probability of exposure $\left(P_{i}\right)$, a frequency $\left(F_{i}\right)$, and an intensity $\left(I_{i}\right)$ for each job $i$. The cumulative index for silica exposure was calculated as $\Sigma D i \times$ $P i \times F_{i} \times I_{i}$ (where $D_{i}$ is the duration of the period of exposure to silica), and was then categorized into four classes, according to the quartiles of the distribution among controls.

The exposure to diesel motor exhaust (DME) was investigated using questionnaires and a cumulative exposure index ( $\mathrm{CEI}_{\mathrm{DME}}$ ) was categorized into three classes (not exposed, low, and high exposure) (see ref [23] for details). 
ICARE's questionnaires were designed with multiple closed questions, allowing the construction of a task-exposure matrix (TEM) specific for asbestos exposure by hygienists.[22] The TEM assigned a probability of exposure (possible, probable, or certain) and an intensity of exposure to each task of interest, according to the exposure period. An asbestos cumulative exposure index (CEI $\left.\mathrm{TEM}_{\mathrm{TE}}\right)$ was calculated by summing the products of the exposure parameters given by the TEM (probability and intensity) and job duration, for each job period, and categorized into four classes according to the quartiles of the distribution among controls.

\section{Statistical analyses}

Overall, 6,481 participants were included in the ICARE study with 2,926 cases and 3,555 controls. Due to the small number of women exposed to wood dust $(n=14)$ we restricted the analysis to men: 2,276 cases and 2,780 controls.

Multivariable unconditional logistic regression models were used to estimate OR and their 95\% CI for the association between lung cancer risk and wood dust exposure. A polynomial regression model was used to estimate OR and 95\% CI by histological type. Both models were adjusted for age at interview/diagnosis (for controls/cases), "département", CSI, number of jobs ( $\leq 3,4,5-6$, and $\geq 7$ jobs, according to the quartiles in controls) and occupational exposure to silica, asbestos, and DME. Additional adjustment for educational level resulted in only marginal changes in ORs estimates; therefore educational level was not included in the models. Interactions between wood dust exposure (ever), and CSI, CEI $I_{\mathrm{TEM}}, \mathrm{CEI}_{\text {silica, }}$ and $\mathrm{CEI}_{\mathrm{DME}}$ were assessed by adding the products terms in the logistic regression model (maximum likelihood ratio test); none of these interactions was statistically significant.

Dose-response relationships were investigated among workers who had completed a specific questionnaire for the total duration of exposure to wood dust, the time between interview/diagnosis and the first exposure. To this end, tests for trend were used if the linearity assumption was satisfied. Statistical analyses were performed using SAS software 9.4 (SAS Institute Inc, Cary, NC, USA).

\section{RESULTS}

A total of 5,056 men were included in this analysis (Table 1). By the mean age, controls were slightly younger (58 years) than cases (60 years). Cases had a statistically significant lower educational level than the controls. We observed a clear increase in lung cancer risk with CSI ( $P$ trend $\left.<10^{-4}\right)$. The two main histological subtypes were squamous cell carcinoma $(n=808,35.3 \%)$ and adenocarcinoma $(n=800,34.9 \%)$.

Overall, 390 cases and 447 controls were exposed to wood dust. 
Table 1. Characteristics of the study population

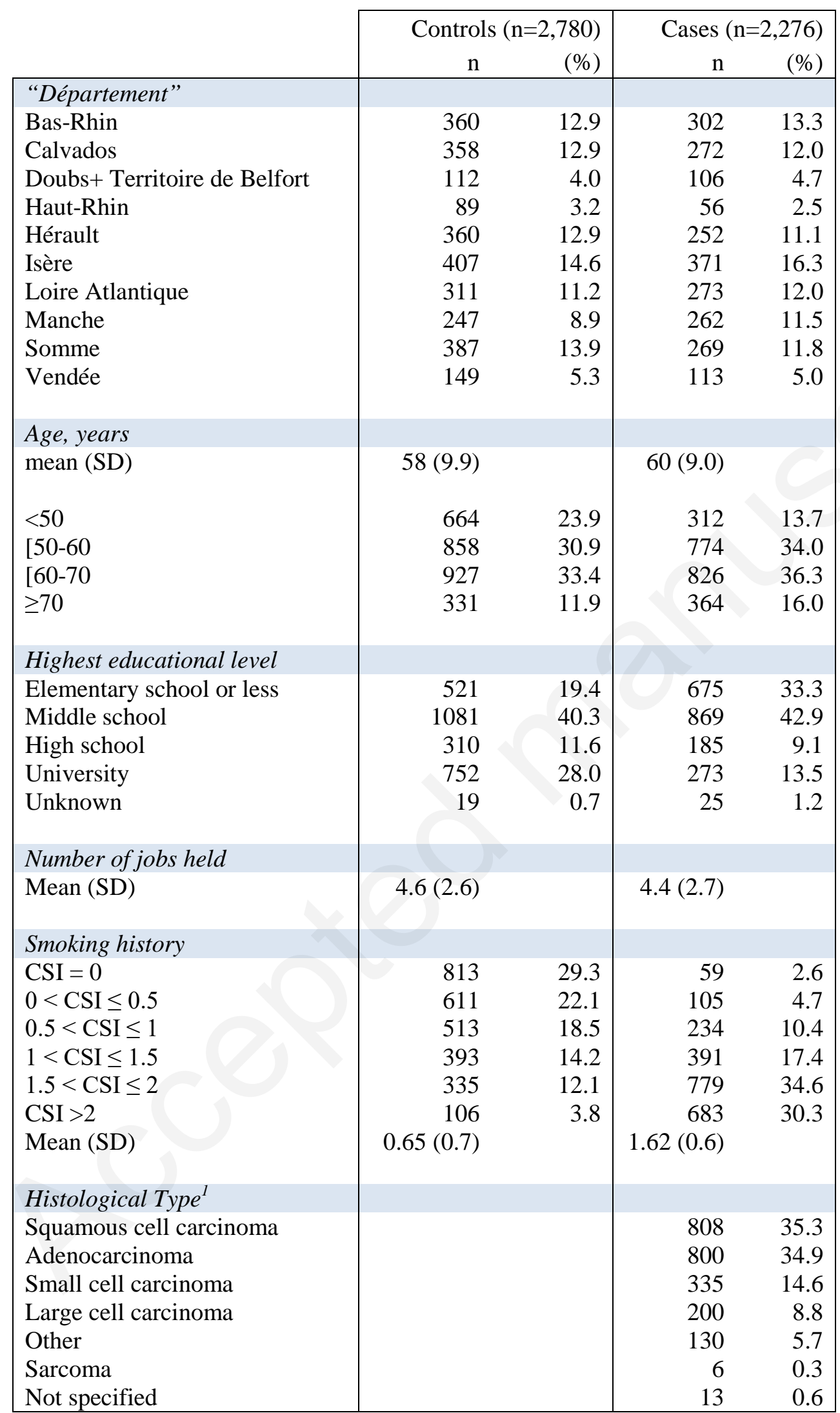

All participants were men.

${ }^{1} 16$ patients had multiple tumors

SD: standard deviation, CSI: comprehensive smoking index 
Table 2 shows the proportion of the industries and occupations of cases exposed to wood dust (workers may have held several jobs). As expected, these workers were employed in typical woodrelated occupations and industries. When this was not the case (e.g. painter or worker in the manufacturing of other transport equipment), the participants were exposed because of their tasks (cutting, sanding, sawing).

Table 2: Number of jobs and industries (n) with more than 10 participants and with more than $10 \%$ of cases exposed to wood dust

\begin{tabular}{|l|l|l|l|}
\hline \multicolumn{2}{|l|}{ Jobs - 2-digit ISCO codes [18] } & $\mathrm{n}$ & $\%$ \\
\hline 8.1 & Cabinetmakers and related woodworkers & 39 & 65 \\
\hline 6.3 & Forestry workers & 14 & 56 \\
\hline 7.3 & Wood preparation workers and paper makers & 22 & 44 \\
\hline 9.5 & Bricklayers, carpenters and other construction workers & 235 & 24 \\
\hline 9.3 & Painters (wood sanding) & 58 & 21 \\
\hline 6.1 & Farmers & 15 & 12 \\
\hline 6.2 & Agricultural and animal husbandry workers & 53 & 12 \\
\hline
\end{tabular}

\begin{tabular}{|l|l|l|l|}
\hline Sectors -2 digit NAF codes [19] & $\mathrm{n}$ & $\%$ \\
\hline 20 & Manufacture of wood and of products of wood & 118 & 71 \\
\hline 02 & Forestry and logging & 13 & 65 \\
\hline 36 & Manufacture of furniture & 40 & 29 \\
\hline 21 & Manufacture of paper and paper products & 11 & 15 \\
\hline 45 & Construction & 227 & 14 \\
\hline 35 & $\begin{array}{l}\text { Manufacture of other transport equipment (activity near carpentry shop or wood } \\
\text { self-cutting) }\end{array}$ & 36 & 13 \\
\hline 01 & $\begin{array}{l}\text { Crop and animal production, hunting and related service activities } \\
\text { (wood cutting) }\end{array}$ & 64 & 12 \\
\hline
\end{tabular}

ISCO: International Standard Classification of Occupations, NAF: Nomenclature d'Activités Françaises (French Nomenclature of activities)

Exposure to wood dust occurred for the first time over 40 years before the diagnosis in participants' career for $49 \%$ of controls and $43 \%$ of the cases. The cases were exposed on average of 17 years and the controls in 15.5 years.

Table 3 shows the lung cancer risk associated with exposure to wood dust. For participants who completed a specific questionnaire (166 controls, 153 cases), the duration of exposure and the time since first exposure were also assessed.

Cases exposed to wood dust over $5 \%$ of the worktime, more than 10 years, and over 40 years since the first exposure showed an increased lung cancer risk. After adjustment for exposure to asbestos, silica and DME, these associations were no longer statistically significant.

The association with wood dust did not differ between different histological types, with ORs (adjusted for occupational exposures) of 1.11, 95\% CI 0.66 to 1.86 for the adenocarcinoma and $1.10,95 \%$ CI 0.66 to 1.85 for squamous cell carcinoma (data not shown). 
Table 3. Risk of lung cancer associated with wood exposure

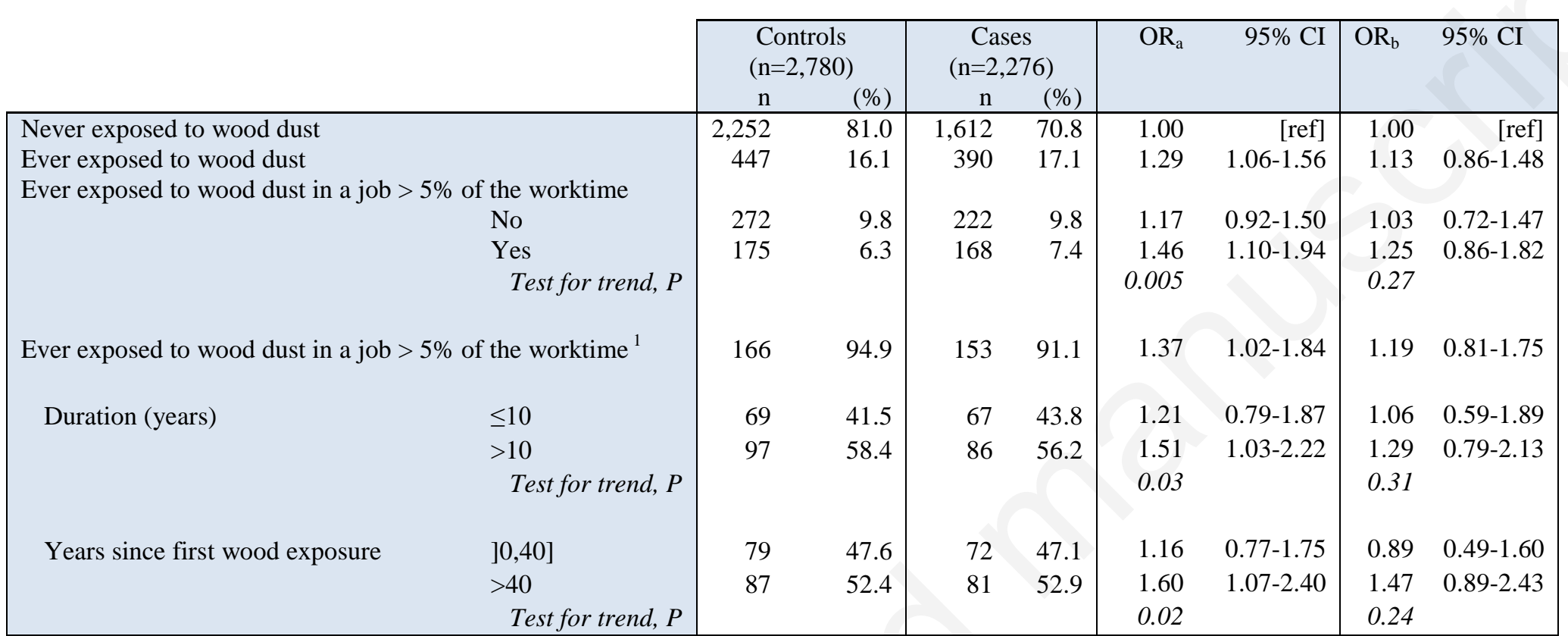

All estimated ORs have been adjusted for age, “département”, number of jobs, CSI (OR $)_{\mathrm{a}}$, further adjusted for asbestos cumulative exposure index (CEI) (CEI $\mathrm{TEM}_{\mathrm{T}}$ ), silica cumulative exposure index $\left(\mathrm{CEI}_{\text {silica }}\right)$ and diesel motor exhaust CEI $\left(\mathrm{CEI}_{\mathrm{DME}}\right)\left(\mathrm{OR}_{\mathrm{b}}\right)$. The class "no wood exposure" is the reference class.

${ }^{1}$ Analysis restricted to participants who completeted a specific questionnaire

OR: odds ratio, CI: confidence interval, CSI: comprehensive smoking index, DME: diesel motor exhaust 
Table 4 shows lung cancer risks among workers who completed a specific questionnaire, according to the wood type (hard and/or softwood and/or exotic and/or composite) and tasks (sanding and/or sawing mechanically or not) that they were exposed to. Few participants reported wearing a mask ( $18 \%$ of cases, $23 \%$ of controls), and only $25 \%$ of controls and cases had suction systems at their workstations. The ORs associated with wood dust exposure were not higher among those who worked indoors and/or had no suction systems.

Few workers were exposed to one type of wood dust only, making it difficult to distinguish any differential effect between soft and hardwood (74\% of cases or controls were exposed to hard and soft wood dust together). Similar ORs were observed for the various types of wood, and they were not statistically significant after adjustment for occupational factors.

When the workers only sawed, the risk increased (OR 1.92, 95\% CI 0.98 to 3.77, when co-exposures were not taken into account, and 3.30, 95\% CI 1.26 to 8.66 when they were considered). Workers who only sanded were too few to allow us to conclude. Wood dust exposure in workers classified as having "non-sawing or non-sanding" tasks was due to their branches of activity or to the tasks of their coworkers, half of them worked indoors.

The lung cancer risk seemed to be slightly increased when the workers sawed or sanded mechanically over 10 years, but no longer significant after adjustment for occupational factors.

The application of any chemicals (creosote, solvents, varnish) was not linked to an excessive lung cancer risk (data not shown). 
Table 4: Risk of lung cancer associated with sanding or sawing the wood

\begin{tabular}{|c|c|c|c|c|c|c|c|c|}
\hline & \multicolumn{2}{|c|}{ Controls $(\mathrm{n}=2,780)$} & \multicolumn{2}{|c|}{ Cases $(n=2,276)$} & \multirow[t]{2}{*}{$\mathrm{OR}_{\mathrm{a}}$} & \multirow[t]{2}{*}{$95 \%$ CI } & \multirow[t]{2}{*}{$\mathrm{OR}$} & \multirow[t]{2}{*}{$95 \% \mathrm{CI}$} \\
\hline & $\mathrm{n}$ & (\%) & $\mathrm{n}$ & (\%) & & & & \\
\hline Never exposed to wood dust & 2,252 & 81.0 & 1,612 & 70.8 & 1.00 & [ref] & 1.00 & [ref] \\
\hline Ever exposed to wood dust in a job $>5 \%$ of the worktime ${ }^{1}$ & 166 & 94.9 & 153 & 91.1 & 1.37 & $1.02-1.84$ & 1.19 & $0.81-1.75$ \\
\hline Worked only indoors & 133 & 80.1 & 125 & 81.7 & 1.37 & 0.99-1.89 & 1.19 & $0.79-1.79$ \\
\hline No suction system at the workstation & 120 & 72.3 & 110 & 71.9 & 1.40 & $1.00-1.97$ & 1.14 & $0.73-1.79$ \\
\hline $\begin{array}{l}\text { Worked only indoors without suction system } \\
\text { Type of wood dust exposure }\end{array}$ & 93 & 56.0 & 87 & 56.9 & 1.43 & $0.97-2.09$ & 1.14 & $0.71-1.85$ \\
\hline Softwood & 148 & 89.2 & 135 & 88.2 & 1.39 & $1.01-1.90$ & 1.20 & $0.80-1.80$ \\
\hline Hardwood & 138 & 83.1 & 127 & 83.0 & 1.34 & 0.98-1.85 & 1.16 & $0.77-1.77$ \\
\hline Exotic wood & 87 & 52.4 & 62 & 40.5 & 1.10 & $0.72-1.67$ & 1.06 & $0.62-1.81$ \\
\hline Composite wood $^{2}$ & 96 & 57.8 & 81 & 52.9 & 1.58 & $1.07-2.32$ & 1.26 & $0.76-2.08$ \\
\hline \multicolumn{9}{|l|}{ Sanding / sawing } \\
\hline Sanding and sawing & 109 & 65.7 & 98 & 64.1 & 1.31 & $0.92-1.88$ & 1.08 & $0.67-1.72$ \\
\hline Only sanding & 8 & 4.8 & 3 & 2.0 & 0.48 & $0.09-2.44$ & 0.41 & $0.07-2.37$ \\
\hline Only sawing & 27 & 16.3 & 32 & 20.9 & 1.92 & $0.98-3.77$ & 3.30 & $1.26-8.66$ \\
\hline Nor sanding nor sawing & 24 & 14.5 & 26 & 17.0 & 1.37 & $0.57-3.28$ & 0.90 & $0.32-2.56$ \\
\hline \multicolumn{9}{|l|}{ Sanding and/or sawing } \\
\hline $\begin{array}{l}\text { Manually }{ }^{3} \\
\text { According to the duration of exposure to wood dust }\end{array}$ & 98 & 48.6 & 93 & 48.2 & 1.33 & $0.91-1.94$ & 1.16 & $0.71-1.90$ \\
\hline$\leq 10$ years & 32 & 32.7 & 36 & According to the duration of exposure to wood dust & 1.42 & $0.76-2.64$ & 0.89 & $0.38-2.10$ \\
\hline$>10$ years & 66 & 67.3 & 57 & 61.3 & 1.28 & $0.80-2.04$ & 1.32 & $0.73-2.37$ \\
\hline Test for trend, $P$ & & & & & 0.26 & & 0.38 & \\
\hline Mechanically $^{4}$ & 129 & 64.6 & 112 & 55.4 & 1.28 & $0.92-1.79$ & 1.14 & $0.73-1.76$ \\
\hline \multicolumn{9}{|l|}{ According to the duration of exposure to wood dust } \\
\hline$\leq 10$ years & 48 & 37.2 & 43 & 38.4 & 1.11 & $0.66-1.85$ & 1.02 & $0.51-2.05$ \\
\hline$>10$ years & 81 & 62.8 & 69 & 61.6 & 1.41 & $0.92-2.16$ & 1.21 & $0.70-2.10$ \\
\hline
\end{tabular}

All estimated ORs have been adjusted for age (at interview for controls, at diagnosis for cases), “département” (geographical areas covered by registry), number of jobs, and CSI $\left(\mathrm{OR}_{\mathrm{a}}\right)$. ORs were further adjusted for silica cumulative exposure index (CEI) $\left(\mathrm{CEI}_{\text {silica }}\right)$, asbestos CEI (CEI $\left.\mathrm{TEM}_{\mathrm{TEM}}\right)$ and diesel motor exhaust CEI $\left(\mathrm{CEI} \mathrm{I}_{\mathrm{DME}}\right)\left(\mathrm{OR}_{\mathrm{b}}\right)$. The class "no wood exposure" is the reference class.

${ }^{1}$ Participants who completed a specific questionnaire

${ }^{2}$ Composite wood include: clipboard, plywood, medium-density fibreboard or melamine 
${ }^{3}$ Among the workers described above $\left({ }^{1}\right)$, whatever the duration of exposure to wood dust.

${ }^{4}$ Among the workers described above $\left({ }^{1}\right)$, whatever the duration of exposure to wood dust.

OR: odds ratio, CI: confidence interval, CSI: comprehensive smoking index, DME: diesel motor exhaust 


\section{DISCUSSION}

Our study showed that occupational wood dust exposure assessed by a specific questionnaire was associated with a slight excess risk of lung cancer when the analyses were not adjusted for occupational exposure to silica, DME and asbestos. The risk increased in workers exposed over $5 \%$ of their worktime in at least one job, with the time since the first exposure. Adjustment for occupational factors weakened these associations, which were no longer statistically significant.

Case-control study is often considered as a weaker design compared with cohort due to recall bias. In our study, wood dust exposure was self-reported and an over-reporting of self-occupational exposures could not be ruled out totally in a situation where participants felt more concerned about their health problems. However, to minimize this bias, the study was aimed to investigate the relationship between environmental exposures and health, and not focused on occupational history. In addition, interviews were conducted by trained interviewers using standardized questionnaires to minimize this bias. Another limitation of our study was the lack of assessment of the exposure level to wood dust and our inability to isolate exclusive exposure to wood species because of few exposed workers.

Our study has several strengths such as the inclusion of incident cases in collaboration with the cancer registries, population-based controls randomly selected from the same "départements" as the cases through incidence density sampling, high response rates of cases and controls. Face-to-face interviews with structured questionnaires allowed for the collection of the entire occupational history as well as an accurate collection of information on carcinogenic exposures such as asbestos, silica or DME.

From a meta-analysis by Hancock et al. and other studies published afterwards, various parameters seem to be important for a study evaluating the role of occupational wood dust exposure in lung cancer risk. These parameters should include sufficient number of cases (for statistical power), a large geographical area to be covered by the study, a direct assessment of smoking history, the entire professional career and a precise identification of occupational exposure to asbestos.[4-12] Other studies about wood dust also used questionnaires.[4-6,8,9,11,12] The exposure to wood dust is known by the workers because it is visible, thus, improving the accuracy of self-report,[24] unlike asbestos exposure for example, which is not visible. Hancock et al. showed, after adjustment for smoking, that wood dust exposure (assessed by a questionnaire) was associated with an increased lung cancer risk (RR 1.3, 95\% CI 1.2 to 1.5).[3]

The increased risk of lung cancer associated with the longest time between the first exposure to wood dust and diagnosis was concordant with the expected latency for lung cancer (over 10 years). However, nearly half of the study population had an exposure to wood dust that was related to their former working conditions. In our study, few participants reported wearing a mask (18\% of cases and $23 \%$ of controls), and $25 \%$ of cases and controls had suction systems at their workstations, similar to that observed in a French study where these protection devices were used (31\% and 21\% respectively).[25] 
As observed by other authors, lung cancer risk associated with wood dust exposure was increased when the occupational exposures were not taken into account.[3] A dose-response relationship was observed between the duration of wood dust exposure and lung cancer by Barcenas et al.[26]: OR 3.0 for those exposed "1-30 years" and 3.4, for “31-45 years" exposure, with a statistically significant trend test $(P=0.0007)$. Corbin et al., among timber processing machine operators, showed a relationship between the duration of employment and lung cancer risk with ORs of 1.1, 4.95, and 14.1 for employment $<2,2-10$ and $>10$ years, respectively ( $P$-trend: 0.03).[27] Other studies found a statistically significant association between wood dust exposure and lung cancer, after adjusting for tobacco and occupational co-exposures:[4,6,11] OR of 1.4, 95\% CI 1.1 to 1.7 for overall exposure,[4] 2.2, 95\% CI 1.3 to 3.6 when workers were regularly exposed over 20 years.[6] Vallières et al. showed that exposure at a substantial level (i.e. medium or high concentrations of over $5 \%$ of their weekly work, and for 5 years or more) was associated with an increased lung cancer risk (1.7, 95\% CI 1.1 to 2.7).[11] In our study, the level of exposure was not available, but indoor work and the absence of a suction system, supposed to be associated with higher levels of wood dust exposure, were not associated with higher risks. Similarly, sanding was usually associated with higher levels of exposure to wood dust.[28, 29] but in our study population, only sawing was associated with an excess lung cancer risk (not observed with sanding only). However we had no information about airborne contamination through cleaning of the machines with compressed air.[28, 30]

In our study, since the workers were exposed to several species, lung cancer risk differences between hardwood and softwood dust exposure could not be determined.

Few studies have focused on the type of wood species. In their meta-analysis, where geographic region was used as a proxy for the tree species type (Nordic countries as a proxy for softwood dust exposure and non-Nordic for mixed hardwood and softwood dust exposure), Hancock et al. showed an increased lung cancer risk in non-Nordic countries (RR 1.3, 95\% CI 1.2 to 1.5) and a reduced risk in the Nordic countries (RR 0.6, 95\% CI 0.4 to 1.0).[3]

\section{CONCLUSION}

The results of this population-based study including a broader range of exposure circumstances to wood dust do not provide a strong support to the hypothesis that wood dust exposure is a risk factor for lung cancer. Our study showed the importance of taking into account co-exposures to other occupational carcinogens in studies on lung cancer. Due to the small number of workers exposed to single wood species, we were not able to determine if exclusive exposure to one type of wood dust was more deleterious than another, as is observed with sinonasal cancers. Further studies taking into account a larger range of occupational and non-occupational risk factors are needed to confirm our findings on the type of wood and work-tasks. 


\section{REFERENCES}

1 Vinck L, Memmi S. Les expositions aux risques professionnels. Les produits chimiques. Enquête SUMER 2010. Direction de l'Animation de la Recherche, des Etudes et des Statistiques.

Synthèse.Stat’ 2015 Juin;13:1-273. $\quad 20$ http://dares.travailemploi.gouv.fr/IMG/pdf/Synthese_Stat_no_13_-_Les_expositions_aux_produits_chimiques.pdf (accessed $4^{\text {th }}$ Mars 2019)

2 International Agency for Research on Cancer (IARC). Arsenic, Metal, Fibers and Dusts. Monographs on the Evaluation of Carcinogenic Risks to Humans. Vol 100C. Lyon, France: International Agency for Research on Cancer, 2012:407-465.

3 Hancock DG, Langley ME, Chia KL, et al. Wood dust exposure and lung cancer risk: a metaanalysis. Occup Environ Med 2016;72:889-898.

4 Brüske-Hohlfeld I, Möhmer M, Pohlabeln H et al. Occupational lung cancer risk for men in Germany: results from a pooled case-control study. Am J Epidemiol 2000;151:384-395.

5 Jahn I, Ahrens W, Brüske-Hohlfeld I et al. Occupational risk factors for lung cancer in women: results of a case-control study in Germany. Am J Ind Med 1999;36:90-100.

6 Jayaprakash V, Natarajan KK, Moysich KB et al. Wood dust exposure and the risk of upper aerodigestive and respiratory cancers in males. Occup Environ Med 2008;65:647-654.

7 Siew SS, Kauppinen T, Kyyrönen P et al. Occupational exposure to wood dust and formaldehyde and risk of nasal, nasopharyngeal, and lung cancer among Finnish men. Cancer Manag Res 2012;4:223-232.

8 Stellman SD, Demers PA, Colin D et al. Cancer mortality and wood dust exposure among participants in the American cancer society cancer prevention study-II (CPS-II). Am J Ind Med $1998 ; 34: 229-237$.

9 Matos E, Vilensky M, Mirabelli D et al. Occupational exposures and lung cancer in Buenos Aires, Argentina. J Occup Environ Med 2000;42:653-659. 
10 Tse LA, Yu ITS, Qiu H et al. Occupational risks and lung cancer burden for Chinese men : a population-based case-referent study. Cancer Causes Control 2012;23:121-131.

11 Vallières E, Pintos J, Parent ME et al. Occupational exposure to wood dust and risk of lung cancer in two population-based case-control studies in Montreal, Canada. Environ Health 2015;14:1-9.

12 Ronco G, Ciccone G, Mirabelli D et al. Occupation and lung cancer in two industrialized areas of northern Italy. Int J Cancer 1988;41:354-358.

13 Ahrens W and F. Merletti F. A standard tool for the analysis of occupational lung cancer in epidemiologic studies. Int J Occup Environ Health 1998;4:236-240.

14 Mirabelli D, Chiusolo M, Calisti R et al. Database of occupations and industrial activities that involve the risk of pulmonary tumors. Epidemiol Prev 2001;25:215-221.

15 Consonni D, DeMatteis S, Lubin JH et al. Lung cancer and occupation in a population-based casecontrol study. Am J Epidemiol 2010;171:323-333.

16 Guida F, Papadopoulos A, Menvielle G et al. Risk of lung cancer and occupational history: results of a French population-based case-control study, the ICARE study. $J$ Occup Environ Med 2011;53:1068-77.

17 Luce D, Stücker I, Icare Study Group. Investigation of occupational and environmental causes of respiratory cancers (ICARE): a multicenter, population-based case-control study in France. BMC Public Health 2011;11:928-937 doi: 10.1186/1471-2458-11-928 [publishd Online: 14 December 2011].

18 International Labour Office. International Standard Classification of Occupations. ${ }^{\text {nd }}$ Ed Geneva, Switzerland,1968:1-415.

19 Institut national de la statistique et des études économiques (INSEE). Nomenclature d'activités françaises: Institut national de la statistique et des études économiques (INSEE). INSEE, Paris, 2000:1-740.

20 Leffondré K, Abrahamowicz M, Siemiatycki J et al. Modeling smoking history using a comprehensive smoking index : Application to lung cancer. Stat Med 2006;25:4132-4146. 
21 Groupe de travail Matgéné. Présentation d'une matrice emplois-exposition aux poussières alvéolaires de silice cristalline libre. Quelques applications à un échantillon de population en France. Saint Maurice: Institut de veille sanitaire; 2010. 6p

22 Guida F, Paget-Bailly S, Lamkarkach F et al. Risk of lung cancer associated with occupational exposure to mineral wools: updating knowledge from a French population-based case-control study, the ICARE study. J Occup Environ Med 2013;55:786-795.

23 Matrat M, Guida F, Cénée S et al. Occupational exposure to Diesel Motor Exhaust and lung cancer : a dose-response relationship hidden by asbestos exposure adjustment ? The ICARE Study. $J$ Cancer Epidemiol 2015; Article ID 879302, 10 pages (http://dx.doi.org/10.1155/2015/879302)

24 Teschke K, Olshan AF, Daniels JL, et al. Occupational exposure assessment in case-control studies : opportunities for improvement. Occup Environ Med 2002;59:575-294

25 Cavet M, Leonard M. Les expositions aux produits chimiques cancérogènes en 2010. Dares Analyses 2013;54 ; https://travail-emploi.gouv.fr/IMG/pdf/2013-054-2.pdf (accessed $11^{\text {th }}$ June 2019)

26 Barcenas $\mathrm{CH}$, Delclos GL, El-Zein R et al. Wood dust exposure and the association with lung cancer risk. Am J Ind Med 2005;47:349-357.

27 Corbin M, McLean D, t’Mannetje A et al. Lung cancer and occupation: a New Zealand cancer registry-based case-control study. Am J Ind Med 2011; 54:89-101

28 Scheeper B, Kromhout H, Boleij JSM. Wood dust exposure during wood-working processes. Ann occup Hyg 1995; 2:141-154

29 Saejiw N, Chaiear N, Sadhra S. Exposure to wood dust and its particle size distribution in a rubberwood sawmill in Thailand. J Occup Environ Hyg 2009; 6:483-490

30 Schlunssen V, Jacobsen G, Erlandsen M et al. Determinants of wood dust exposure in the Danish furniture industry - Results from two cross-sectional studies 6 years apart. Ann Occup Hyg 2008; $52: 227-238$ 


\title{
STATEMENTS
}

\section{Ethics approval statement}

The study was approved by the Institutional Review Board of the French National Institute of Health and Medical Research (IRB-INSERM, n ${ }^{\circ} 01-036$ ) and by the French Data Protection Authority (CNIL $\left.n^{\circ} 90120\right)$.

\section{Funding}

This work was supported by the French Agency of Health Security (ANSES), the Foundation of France, the French National Research Agency (ANR), the National Institute of Cancer (INCA), the Foundation of Medical Research (FRM), the French Institute for Public Health Survey (InVS), the Health Ministry (DGS), the Agency for Research on Cancer (ARC), and the French Ministry of Work, Solidarity and Public Function (DGT)

\section{Competing Interests}

No competing interests

\section{Contributorship}

Mireille Matrat : statistical analysis, results, drafting

Loredana Radoï : help for results and help for drafting

Joëlle Févotte : questionnaires

Florence Guida : creation of the asbestos Task Exposure Matrix, data management

Sylvie Cénée : data management

Diane Cyr : data management

Marie Sanchez : data management

Gwenn Menvielle : rereading

Annie Schmaus : data management

Emilie Marrer : histological analysis

Danièle Luce : design of the study, help for results and drafting

Isabelle Stücker: design of the study

\section{Acknowledgments}

To members of ICARE Study: Anne-Valérie Guizard (Registre des cancers du Calvados, France); Arlette Danzon, Anne-Sophie Woronoff (Registre des cancers du Doubs et du Territoire de Belfort, France); Velten Michel (Registre des cancers du Bas-Rhin, France); Antoine Buemi, Émilie Marrer (Registre des cancers du Haut-Rhin, France); Brigitte Tretarre (Registre des cancers de l'Hérault, France); Marc Colonna, Patricia Delafosse (Registre des cancers de l’Isère, France); Paolo Bercelli, Florence Molinie (Registre des cancers de Loire-Atlantique-Vendée, France); Simona Bara (Registre des cancers de la Manche, France); Bénédicte Lapotre-Ledoux, Nicole Raverdy (Registre des cancers de la Somme, France); Oumar Gaye, Farida Lamkarkach (Inserm, Centre for Research in Epidemiology and Population Health (CESP), U1018, Environmental Epidemiology of Cancer Team, F-94807, Villejuif, France), Corinne Pilorget (Institut national de Veille Sanitaire (InVS), 94410 SaintMaurice, France).

\author{
Abbreviations \\ CEI: Cumulative Exposure Index \\ CI: Confidence Interval \\ CNIL : Commission Nationale de l'Informatique et des Libertés (French Data Protection Authority) \\ CSI : comprehensive smoking index \\ DME : Diesel Motor Exhaust \\ IARC: International Agency for Research on Cancer \\ ICARE: Investigations sur les CAncers Respiratoires et de l'Environnement \\ ICD-O : International Classification of Diseases for Oncology \\ IRB-INSERM: Institutional Review Board of the French National Institute of Health and Medical \\ Research
}


ISCO: International Standard Classification of Occupations

JEM: Job-Exposure Matrix

NAF: Nomenclatures d'Activités Française (French Nomenclatures of Activities)

OR: Odds Ratio

Ref: Reference

RR: Relative Risk

SD: Standard Deviation

TEM: Task-Exposure Matrix 